Check for updates

Cite this: RSC Adv., 2017, 7, 27737

\section{Synthesis and biological evaluation of $(E)-4-(3-$ arylvinyl-1 $H$-indazol-6-yl)pyrimidin-2-amine derivatives as PLK4 inhibitors for the treatment of breast cancer $\dagger$}

\author{
Zhihao Liu, Qian Lei, W Wei Wei, Lu Xiong, Yaojie Shi, Guoyi Yan, Chao Gao, \\ Tinghong Ye, Ningyu Wang* and Luoting Yu (D)*
}

Polo-like kinase 4 (PLK4), a vital regulator of centriole duplication, is important for maintaining genome stability. Dysregulation of PLK4 has been found in several human cancers and is associated with a predisposition to tumorigenesis. Herein, we describe the discovery of (E)-4-(3-arylvinyl- $1 \mathrm{H}$-indazol-6-yl) pyrimidin-2-amine derivatives as potent PLK4 inhibitors with more concise structure using a scaffold hopping strategy. SAR exploration and preliminary assessment identified 14i as a new PLK4 inhibitor which displayed excellent potency in vitro. 14i could inhibit the activity of PLK4, perturb centriole replication, result in mitosis disorder and induce cell apoptosis in breast cancer cells. Moreover 14i demonstrated significant antitumor efficacy in the MDA-MB-468 and MDA-MB-231 xenograft models. This study suggested that this concise chemotype would represent a promising scaffold of PLK4 inhibitors for cancer therapy and 14i would be an attractive lead compound for further optimization and evaluation.
Received 1st March 2017 Accepted 16th May 2017 DOI: 10.1039/c7ra02518a

rsc.li/rsc-advances
Dysregulation of PLK4 often causes disorder of centrosome duplication and aneuploidy formation, thereby promoting genomic instability which is a characteristic observed in many types of cancers. ${ }^{15,16}$ Depletion of PLK4 by RNA interference in breast cancer cells and xenografts induces cell apoptosis and tumor growth suppression. ${ }^{\mathbf{1 6}}$ Besides, PLK4 is crucial to PTENdeficient cancer cells for survival suggesting that there is a synthetic lethal interaction between PLK4 and PTEN in breast cancer cells. ${ }^{17,18}$ Thus, PLK4 could be a potential target for breast cancer and draw our attention to discover PLK4 inhibitors as candidates against breast cancer.

Some typical PLK4 inhibitors are shown in Fig. 1. Multikinase inhibitor 1 (R1530) has been shown to be potent against PLK4 with an $\mathrm{IC}_{50}$ value of $6 \mathrm{nM}$. It could promote cancer cells genomic instability and facilitate cancer cells sensitive to chemotherapy. ${ }^{19} 2$ (Centrinone), a selective PLK4 inhibitor, could result in a p53-dependent cell cycle arrest in G1. ${ }^{20}$ And 3 (Axitinib), a well-known pan-VEGFR inhibitor, has been approved for renal cell carcinoma (RCC) by FDA and demonstrated collateral inhibitory activity against PLK4 with a $K_{\mathrm{i}}$ value of 4.2 nM. $^{21}$ Recently, 4 (CFI-400437) with a scaffold of (E)-3((1H-indazol-6-yl)methylene)indolin-2-ones was reported to be a PLK4 inhibitor with an $\mathrm{IC}_{50}$ value of $6 \mathrm{nM},{ }^{22}$ and its spirooxindole counterparts 5, 6, and 7 exhibited excellent selectivity and potency. ${ }^{23-25} 6$ (CFI-400945) has demonstrated significant efficacy in animal models of breast cancer, colorectal cancer and pancreatic cancer, especially in PTEN-deficient cancer patient-derived xenografts. ${ }^{17,24,26}$
State Key Laboratory of Biotherapy and Cancer Center, West China Hospital, West China Medical School, Sichuan University and Collaborative Innovation Center, Chengdu 610041, China.E-mail: yuluot@scu.edu.cn; ningyuwang_sklb@scu.edu.cn; Fax: +8628 8516 4060; Tel: +862885164063

$\dagger$ Electronic supplementary information (ESI) available. See DOI: 10.1039/c7ra02518a

\$ These authors contributed equally. 


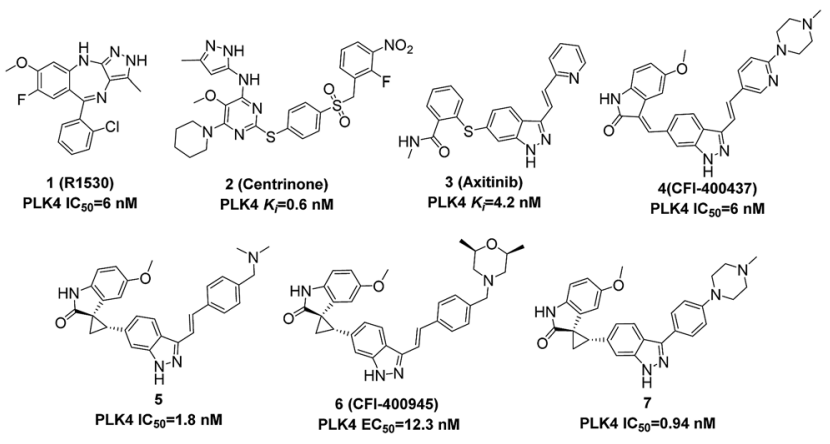

Fig. 1 Chemical structures of representative PLK4 inhibitors.

To our knowledge, the reported scaffolds of PLK4 inhibitors are not diverse. What is more, although some bioactive molecules such as 1 (R1530) and 3 (Axitinib) demonstrated good inhibitory activity against PLK4, their main targets are not PLK4. Despite preferentially isolated as the $E$-isomer, the indazolylmethyleneindolinone compound $\mathbf{4}$ has the potential to isomerize in vivo. ${ }^{23} 5,6$, and 7 , as the spirooxindole counterparts of 4, own improved configurational stability and physicochemical properties, but their synthesis and purification are more complicated due to the spirooxindole motif with multiple chiral centers. ${ }^{27}$ Based on above status quo, we wished to explore a more concise scaffold of selective PLK4 inhibitors.

We firstly investigated the co-crystallization structure (PDB code 4JXF) to understand interactions between 5 and PLK4 kinase domain (Fig. 2). As a hinge binder, indazole ring of $\mathbf{5}$ formed two hydrogen bonds with the backbone carbonyl of Cys92 and NH of Glu90 in the hinge region. The arylvinyl group potentially fit into the solvent-exposed side of the adenine binding pocket, and the aryl fragment had a strong $\pi$-cation interaction with amino of Arg28. It is notable that all of 3, 4, 6 have the same motif of $(E)$-3-arylvinyl- $1 H$-indazole as 5 . Moreover, the carbonyl and $\mathrm{NH}$ of oxindole in $\mathbf{5}$ could form hydrogen bonds with side chain of Lys41 and the backbone carbonyl of Gln160, respectively. And 3, 4, 6 also have corresponding fragments to

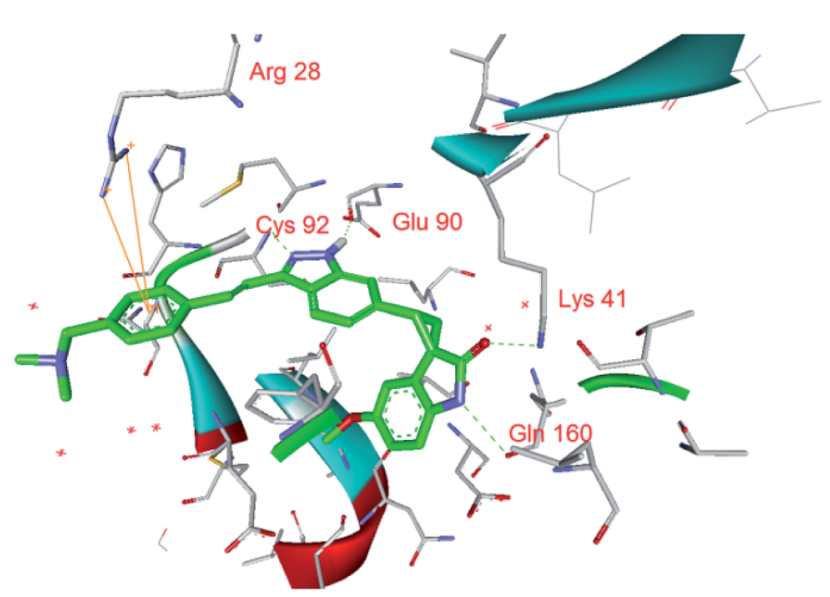

Fig. 2 X-ray crystal structure of 5 in the active site of PLK4 with interactions to the key residues (PDB code 4JXF). interact potentially with both these two amino acid residues (Fig. 3). Hence, we speculated that 3-6 might interact with PLK4 kinase domain in the same binding mode.

Based on above analyses, to quest for a new and concise chemotype of PLK4 inhibitors, we kept $(E)$-3-arylvinyl-1H-indazole motif as hinge binder and focused on utilizing scaffold hopping strategy to simplify the skeletons at 6-position of indazole in 3-6 simultaneously retaining pharmacophores which could form H-bonds with Lys41 and Gln160 in our preconceived scaffold. After careful consideration, we cautiously incorporated 2-aminepyrimidin-4-yl at 6-position of indazole in order to facilitate interactions between compounds and PLK4 (Fig. 3). Herein we report the design, synthesis and biology evaluation of (E)-4-(3-arylvinyl-1H-indazol-6-yl)pyrimidin-2amine derivatives as potent PLK4 inhibitors.

\section{Results and discussion}

\section{Synthesis}

The synthesis of target compounds 14a-14y and 15a-15d is depicted in Scheme 1. Commercially available 6-bromo- $1 \mathrm{H}$ indazoles $\mathbf{8 a - 8 b}$ were reacted with bis(pinacolato)diboron using $\mathrm{Pd}(\mathrm{dppf}) \mathrm{Cl}_{2}$ and potassium acetate in dioxane at $90{ }^{\circ} \mathrm{C}$ respectively to afford corresponding boronic acid pinacol esters $\mathbf{9 a - 9 b}$. Suzuki coupling of $\mathbf{9 a - 9 b}$ with $\mathbf{1 0 a - 1 0 c}$ respectively provided products 11a-11d. Then iodination of 11a-11d was carried out in $\mathrm{DMF}$ at $60{ }^{\circ} \mathrm{C}$ overnight and provided a good yield of intermediates 12a-12d. At last, Suzuki coupling of 12a-12d with transhetarylvinylboronates 13a-13y using $\mathrm{Pd}(\mathrm{dppf}) \mathrm{Cl}_{2}$ and cesium carbonate afforded target products $14 a-14 y$ and $\mathbf{1 5 a}-\mathbf{1 5 d}$.

\section{Study on SAR}

The title compounds were evaluated for their PLK4 potency as well as anti-proliferative potencies against MDA-MB-231 and MDA-MB-468 cell lines, and 3 (Axitinib) was used as a positive control. Axitinib demonstrated PLK4 potency with an $\mathrm{IC}_{50}$ value of $41.3 \mathrm{nM}$ and moderate anti-proliferative activities against MDA-MB-231 and MDA-MB-468 cell lines. The SAR study began with the terminal aryl group of arylvinyl indazole motif. Compared with 3 (Axitinib), 14a containing a single phenyl displayed moderate PLK4 potency with an $\mathrm{IC}_{50}$ value of $74.9 \mathrm{nM}$, and it also exhibited anti-proliferative activities against MDAMB-231 and MDA-MB-468 cell lines $\left(\mathrm{IC}_{50}=6.2\right.$ and $8.7 \mu \mathrm{M}$, respectively), implying that our scaffold hopping strategy was feasible. Incorporation of a methoxy group at the 4-position of phenyl ring in 14a improved PLK4 potency but its cellular activity declined (14b), 3-methylamino substituted analogue 14c showed similar PLK4 potency with 14a. The phenyl ring in 14a replaced with indole (14d) resulted in a dramatic drop in PLK4 potency although its cellular activity improved slightly. Substituents on para-position of the phenyl ring with hydrophilic groups such as morpholino (14e) and $N$-methylpiperazine (14f) improved both PLK4 and cellular activities dramatically. The same tendency could also be observed in benzyl analogues 14g, 14h and 14i. However, meta-substituted phenyl analogues (14j, 14k) exhibited declined PLK4 and cellular activities, 

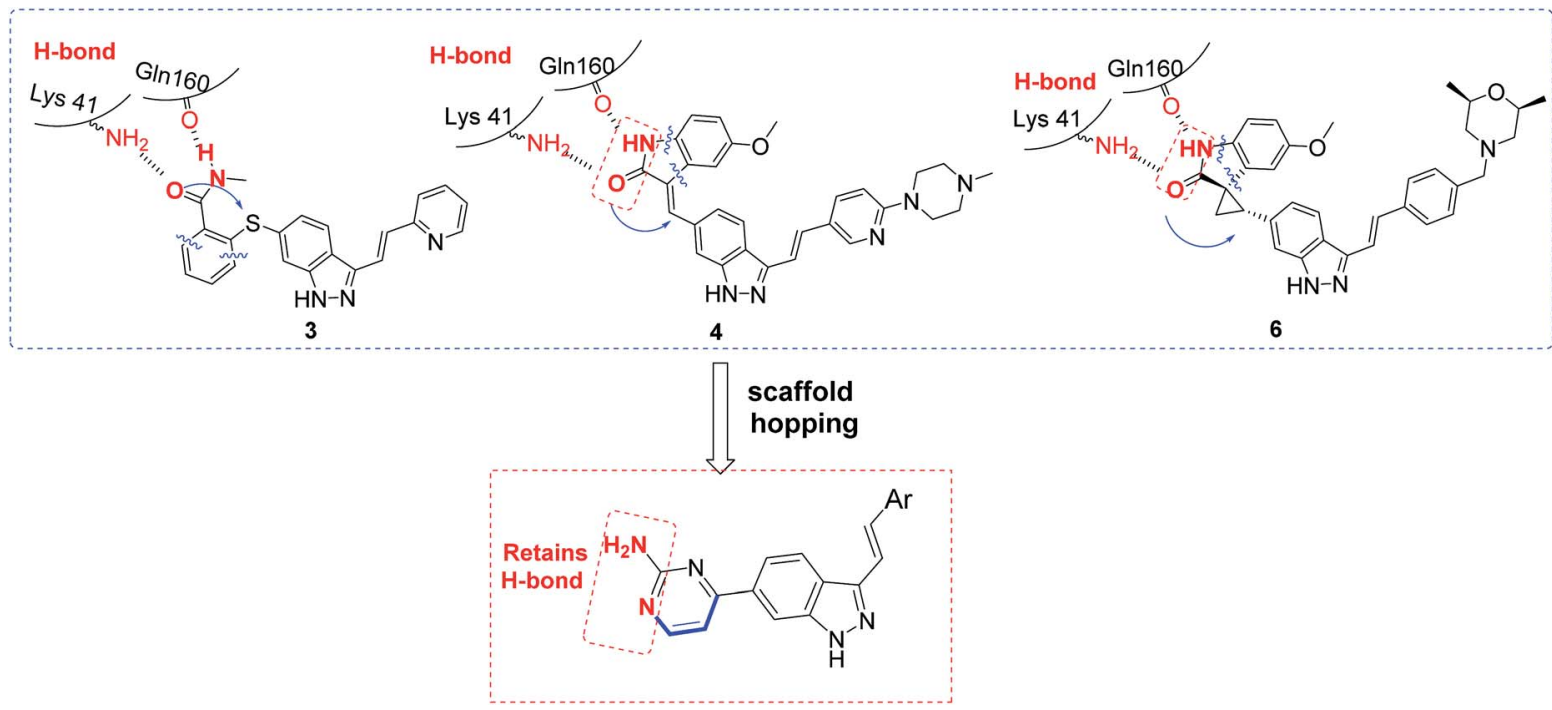

Fig. 3 Designed strategy of title molecules.

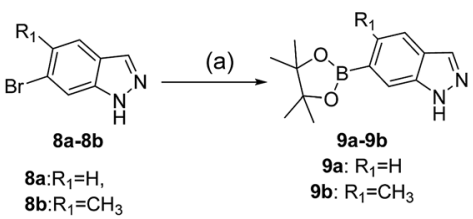

8b: $\mathrm{R}_{1}=\mathrm{CH}_{3}$

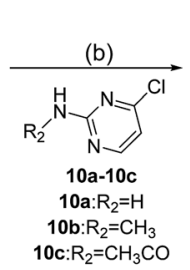

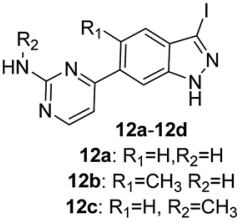

12d: $\mathrm{R}_{1}=\mathrm{H}, \mathrm{R}_{2}=\mathrm{CH}_{3} \mathrm{CO}$

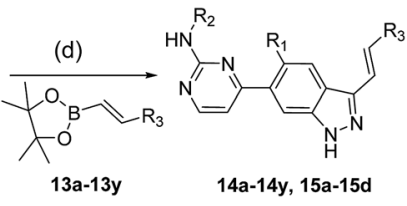

11b: $\mathrm{R}_{1}=\mathrm{CH}_{3} \mathrm{R}_{2}=\mathrm{H}$

11c: $\mathrm{R}_{1}=\mathrm{H}, \mathrm{R}_{2}=\mathrm{CH}_{3}$

\section{(c)}

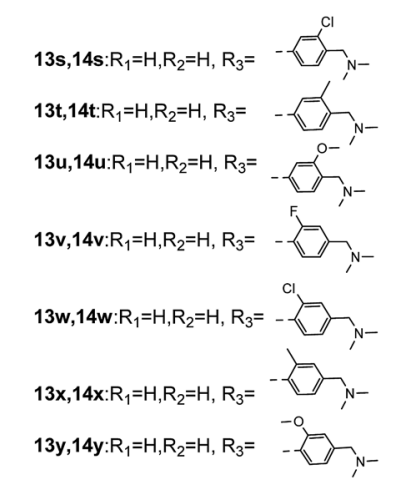

15a: $\mathrm{R}_{1}=\mathrm{H}, \mathrm{R}_{2}=\mathrm{CH}_{3} \mathrm{CO}, \mathrm{R}_{3}=-\square$ $15 b: R_{1}=\mathrm{H}, \mathrm{R}_{2}=\mathrm{CH}_{3} \mathrm{CO}, \mathrm{R}_{3}=$, If 15c: $\mathrm{R}_{1}=H, \mathrm{R}_{2}=\mathrm{CH}_{3}, \mathrm{R}_{3}=$ $15 \mathrm{~d}: \mathrm{R}_{1}=\mathrm{CH}_{3}, \mathrm{R}_{2}=\mathrm{H}, \mathrm{R}_{3}=-\mathrm{N}_{\mathrm{N}}^{-}$

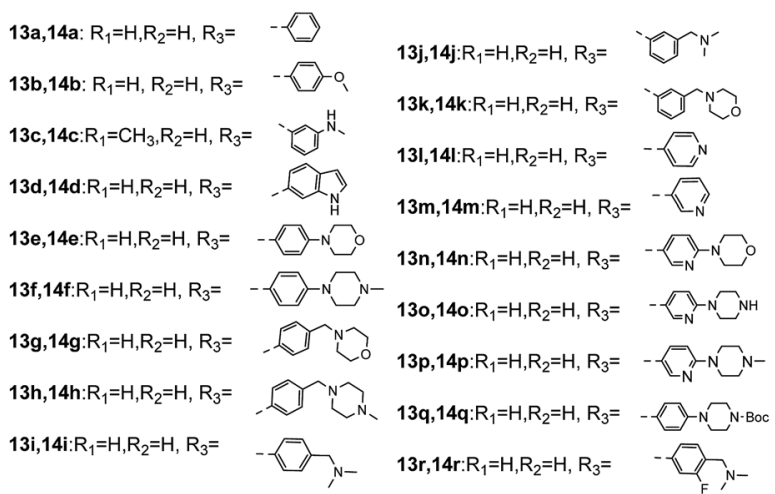

Scheme 1 Synthetic route of title compounds $14 a-14 y, 15 a-15 d$. Reagents and conditions: (a) bis(Pinacolato)diboron, $\mathrm{AcOK}, \mathrm{Pd}(\mathrm{dppf}) \mathrm{Cl}_{2}$, dioxane, $90{ }^{\circ} \mathrm{C}$; (b) $\mathrm{Pd}(\mathrm{dppf}) \mathrm{Cl}_{2}, \mathrm{~K}_{2} \mathrm{CO}_{3}$, dioxane : $\mathrm{H}_{2} \mathrm{O}=4: 1,95^{\circ} \mathrm{C}$; (c) $\mathrm{I}_{2}, \mathrm{~K}_{2} \mathrm{CO}_{3}, \mathrm{DMF}, 60{ }^{\circ} \mathrm{C}$; (d) $\mathrm{Pd}(\mathrm{dppf}) \mathrm{Cl}_{2}, \mathrm{Cs}_{2} \mathrm{CO}_{3}$, dioxane : $\mathrm{H}_{2} \mathrm{O}=4: 1$, $100{ }^{\circ} \mathrm{C}$.

suggesting that the orientation of hydrophilic groups is very important for the interaction with PLK4.

The pyridin-3(or 4)-yl analogues 141 and $\mathbf{1 4 m}$ were slightly better than 14a in activity. The $\mathrm{H}$ atom at 2-position of pyridine in $\mathbf{1 4 m}$ replaced with morpholino group (14n) or piperazinyl group (140) improved the activity, but both PLK4 and cellular potencies declined with the increasing size of substituents, as exemplified by the $N$-methylpiperazinyl (14p) and $N$-Bocpiperazinyl (14q) analogues, suggesting a suitable size of group on this position was favorable. Among these compounds, 14i demonstrated excellent inhibitory activity against PLK4 $\left(\mathrm{IC}_{50}=\right.$ $11.2 \mathrm{nM}$ ) and good potencies against MDA-MB-231 and MDA-
MB-468 cell lines $\left(\mathrm{IC}_{50}=0.09\right.$ and $0.06 \mu \mathrm{M}$, respectively). Then the influence of substituents on 2- and 3-position of the phenyl ring in $\mathbf{1 4} \mathbf{i}$ was investigated. Introduction of fluorine atom (14r \& 14v), chlorine atom (14s \& 14w), methyl group (14t \& $\mathbf{1 4 x})$ and methoxy (14u \& 14y) on 2-position or 3-position impaired the enzymatic potency to the same extent, but a sharp loss of cellular potency was observed with respect to the 2substituted groups $(\mathbf{1 4 r}-\mathbf{1 4 u})$. These results indicated it is the steric effect rather than the electric effect of substituents on the phenyl ring that was crucial to the PLK4 potency, because the hydrophobic pocket near the phenyl ring might be too narrow to accommodate any bulky substituents (Table 1). 
Next, we investigated the influence of substituents on pyrimidin-2-amine and 5-position of indazole ring based on the structure of $14 \mathbf{i}$ (Table 2). The acetamino analogues of $14 \mathbf{i}$ or $14 \mathbf{r}$ (15a, 15b) and the methylamino analogue of $14 \mathbf{i}(\mathbf{1 5 c})$ were slightly less potent than their corresponding counterparts, suggesting that substituents on this position might be tolerated. Introduction of methyl group at 5-position of indazole ring (15d) resulted in a dramatic drop in PLK4 potency $\left(\mathrm{IC}_{50}=956\right.$ $\mathrm{nM}$ ) and antiproliferative activities against MDA-MB-231 and MDA-MB-468 cell lines ( $\mathrm{IC}_{50}=8.60$ and $5.43 \mu \mathrm{M}$, respectively). Interestingly, almost all of these compounds showed better anti-proliferative effects against MDA-MB-468 (PTEN-deficient cancer cells) than MDA-MB-231 (PTEN-wild type cancer cells), which implicated that PTEN deficient breast cancer cells could be more sensitive to PLK4 inhibitors like 14i because of the synthetic lethal interaction between PLK4 and PTEN.

\section{Solubility, $\operatorname{Clog} P$ and LLE evaluation}

Due to the preference of in vitro enzymatic and cellular potencies, compounds 14i, 14r, and 15a were selected to evaluate their solubility in water under different $\mathrm{pH}$. And another two

Table 1 SAR of $14 a-14 y^{a}$

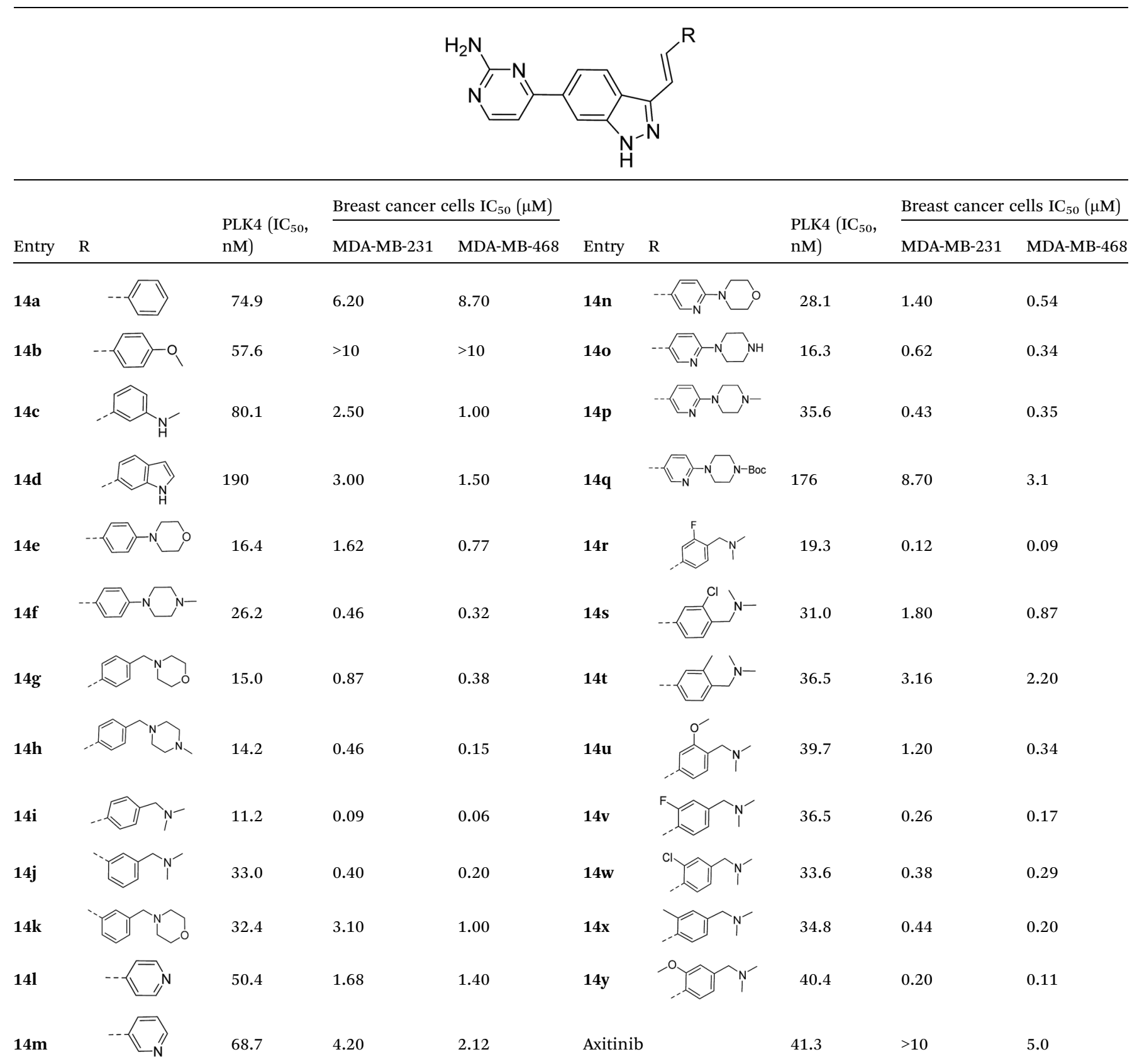

${ }^{a}$ PLK4 IC $_{50}$ values were determined from Kinase Profiler of Reaction Biology Corporation and all activity data represent the mean values of two independent experiments. 


\begin{tabular}{|c|c|c|c|c|c|c|}
\hline \multirow[b]{2}{*}{ Entry } & \multirow[b]{2}{*}{$\mathrm{R}_{1}$} & \multirow[b]{2}{*}{$\mathrm{R}_{2}$} & \multirow[b]{2}{*}{$\mathrm{R}_{3}$} & \multirow{2}{*}{$\begin{array}{l}\text { PLK4 }\left(\mathrm{IC}_{50}\right. \\
\mathrm{nM})\end{array}$} & \multicolumn{2}{|c|}{ Breast cancer cells $\mathrm{IC}_{50}(\mu \mathrm{M})$} \\
\hline & & & & & MDA-MB-231 & MDA-MB-468 \\
\hline $15 a$ & & & $\mathrm{H}-$ & 22.2 & 0.18 & 0.10 \\
\hline $15 b$ & & & $\mathrm{H}-$ & 54.5 & 0.30 & 0.14 \\
\hline $15 \mathrm{c}$ & & $\mathrm{CH}_{3-}$ & $\mathrm{H}-$ & 164 & 2.90 & 2.78 \\
\hline 15d & & $\mathrm{H}-$ & $\mathrm{CH}_{3}^{-}$ & 956 & 8.60 & 5.43 \\
\hline $14 \mathbf{i}$ & & $\mathrm{H}^{-}$ & $\mathrm{H}^{-}$ & 11.2 & 0.09 & 0.06 \\
\hline
\end{tabular}

\footnotetext{
${ }^{a}$ PLK4 IC $_{50}$ values were determined from Kinase Profiler of Reaction Biology Corporation and all activity data represent the mean values of two independent experiments.
}

important parameters of drug-likeness, $\operatorname{Clog} P$ and LLE (ligandlipophilicity efficiency), were also calculated ${ }^{28}$ (Table 3).

Both compounds 14i and 15a exhibited comparable Clog $P$ and LLE, as well as solubility in $\mathrm{H}_{2} \mathrm{O}$, which were much better than 14r. 14i was finally selected for further evaluation because of its excellent in vitro activity and molecular properties.

Table 3 Clog $P$, LLE and solubility of $14 i, 14 r$ and $15 a$

\begin{tabular}{|c|c|c|c|c|c|}
\hline \multirow[b]{2}{*}{ Entry } & \multirow[b]{2}{*}{$\operatorname{Clog} P^{a}$} & \multirow[b]{2}{*}{$\operatorname{LLE}^{a}$} & \multicolumn{3}{|c|}{ Solubility $\left(\mu \mathrm{g} \mathrm{mL}{ }^{-1}\right)$} \\
\hline & & & $\begin{array}{l}(\mathrm{pH}= \\
6.8)\end{array}$ & $\mathrm{pH}=4.3$ & $\mathrm{pH}=9.0$ \\
\hline $14 \mathrm{i}$ & 3.78 & 4.17 & 109.80 & 2209.84 & 18.68 \\
\hline $14 r$ & 3.93 & 3.78 & 12.91 & 1499.70 & 1.52 \\
\hline $15 a$ & 33 & 4.32 & 134.43 & 7336.41 & 9.37 \\
\hline
\end{tabular}

${ }^{a} \mathrm{Clog} P$ : calculate by CambridgeSoft-PerkinElmer's ChemBioDraw Ultra version 12.0; LLE $=$ pIC $_{50}$ PLK4-Clog $P$ (ref. 28).

Table 4 The selectivity of $14 \mathrm{i}$ for polo-like kinase family ${ }^{a}$

\begin{tabular}{lllll}
\hline & \multicolumn{2}{l}{ Inh\% $(100 \mathrm{nM})$} & & \\
\cline { 2 - 5 } Entry & PLK1 & PLK2 & PLK3 & PLK4 \\
\hline $\mathbf{1 4}$ i & 3.59 & 45.08 & 2.99 & 96.21
\end{tabular}

${ }^{a}$ Note: all compounds were tested at ATP concentration of $10 \mu \mathrm{M}$. The percent of inhibition is an average of two independent titrations. PLK5 does not have kinase domain, so it wasn't tested.
Besides, 14i also exhibited good selectivity for PLK4 over other members of polo-like kinase family (Table 4).

\section{Molecular docking of $14 i$ with PLK4}

To understand the interaction of $(E)$-4-(3-arylvinyl-1H-indazol-6yl)pyrimidin-2-amine derivatives with PLK4, we modelled the binding mode of 14i in the ATP pocket using a reported crystal structure of the PLK4 kinase domain (PDB ID: 4JXF). As shown in Fig. 4, 14i maintained H-bonding interactions with PLK4 at the backbone carbonyl of Cys92 and NH of Glu90 in the hinge region. Interestingly, unlike 5, the amino group of $\mathbf{1 4 i}$ formed two hydrogen bonds with the backbone carbonyls of Gln160 and Ala153, and the $\mathrm{N}$ atom of 1-pyrimidine in $\mathbf{1 4} \mathbf{i}$ had an

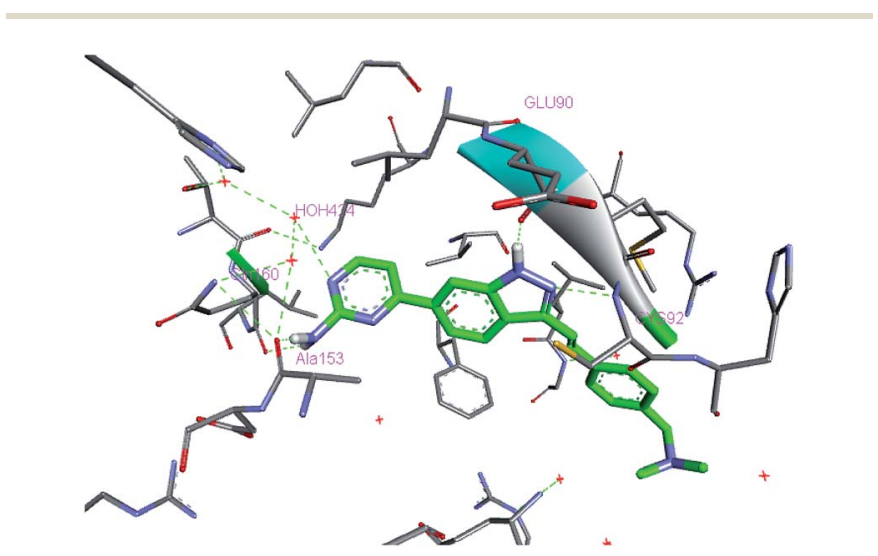

Fig. 4 Proposed binding mode of compound 14i to the PLK4 kinase domain. 
interaction with crystalline water $(\mathrm{HOH} 424)$ instead of forming $\mathrm{H}$-bond with Lys41. Furthermore, trans-arylvinyl group in 14i potentially extended to the solvent-exposed side. Overall, 14i could fit well into the ATP pocket of PLK4, which enable it to be a potent PLK4 inhibitor.

\section{Inhibition of centriole duplication and mitosis by $14 \mathrm{i}$}

Because of the crucial role of PLK4 in centriole duplication, we examined the effect of $\mathbf{1 4}$ i on centriole duplication in MDA-MB468 and MDA-MB-231 cell lines by immunostaining DAPI, centrin 2 and $\gamma$-tubulin to visualize cell nucleus (blue), centriole (green) and mitotic spindle (red) respectively. After $48 \mathrm{~h}$ exposure with 14i, cells with disordered centrosome replication increased in a dose-dependent manner (Fig. 5A), and $0.5 \mu \mathrm{M}$ of $14 i$ distinctly inhibited centrosome replication (Fig. 5B).

By analysis of DNA content of MDA-MB-468 and MDA-MB-231 cells using flow cytometry, we found $\mathbf{1 4 i}$ induced polyploid formation in a dose-dependent manner (Fig. 6A), suggesting that 14i could result in mitotic disorder and promote genomic instability. Moreover, immunoblot analysis displayed the increase of activated cleaved-caspase- 3 which represents the activation of apoptotic pathways and the reduction of $\mathrm{P}-\mathrm{H} 3$ which indicates the unsmooth progression of mitosis in a does dependent manner after treated with 14i (Fig. 6B and C). Overall, 14i inhibited the activity of PLK4 thereby perturb the centriole

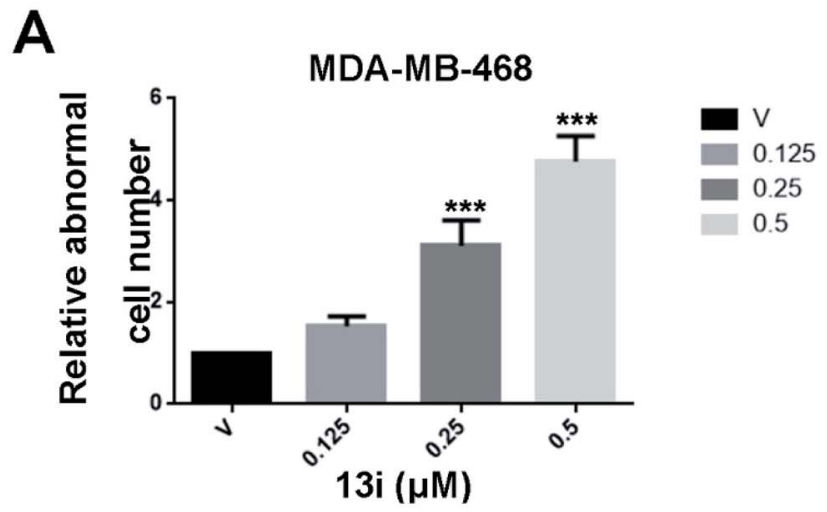

B

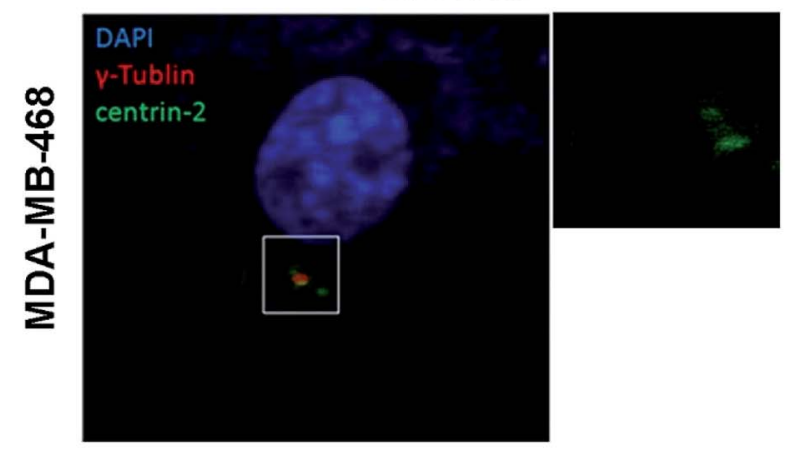

Vehicle
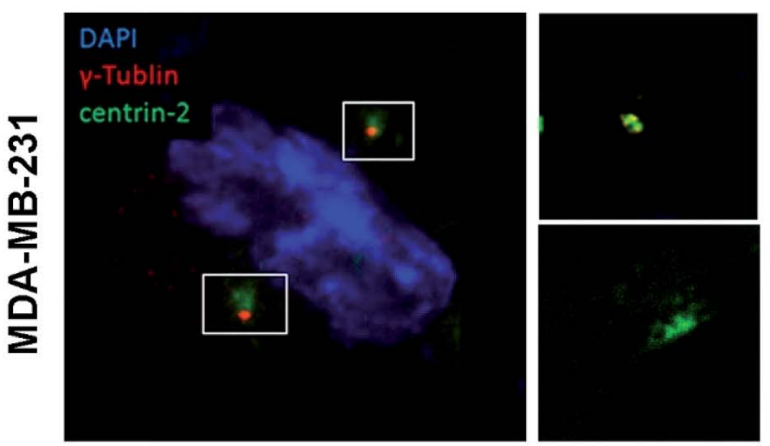

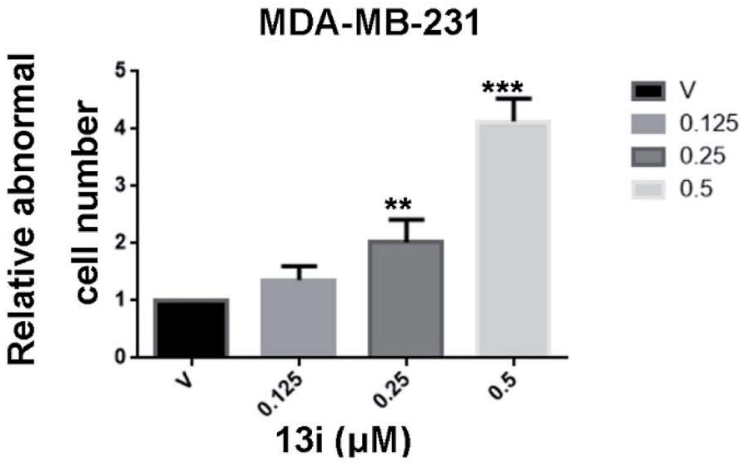

$0.5 \mu \mathrm{M} 13 \mathrm{i}$

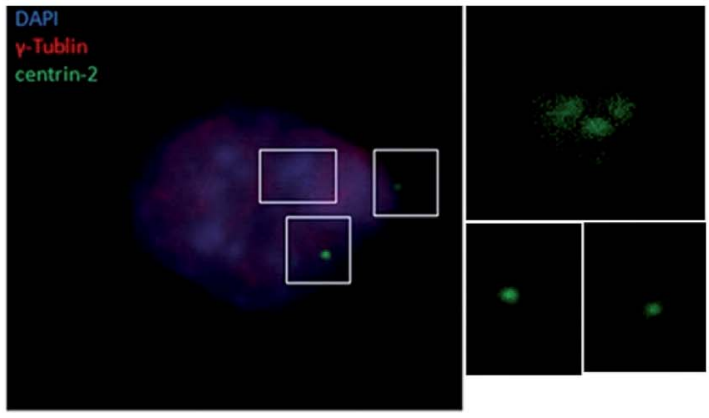

\section{$0.5 \mu \mathrm{M} 13 \mathrm{i}$}

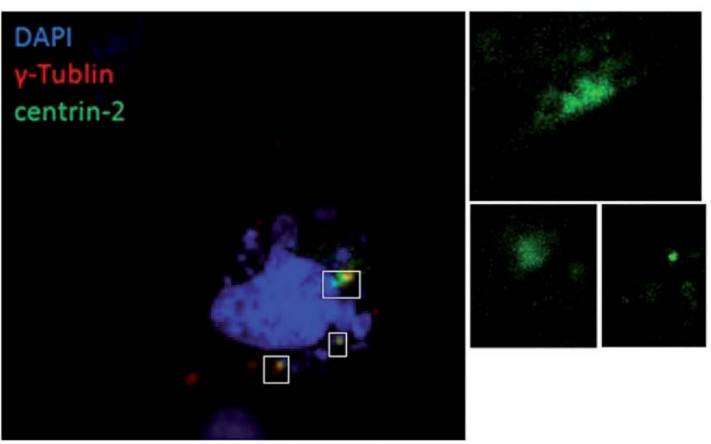

Fig. 5 (A) Cell numbers of abnormal centrosome replication after treated with $14 \mathrm{i}$. (B) Effects of $14 \mathrm{i}$ on perturbing centrosome replication by immunofluorescence. MDA-MB-468 and MDA-MB-231 cells were treated with 14i or DMSO for $48 \mathrm{~h}$. Cells were stained with centrin2, $\gamma$-tubulin, and DAPI. Insets show higher magnification views of the centrioles (boxed regions). 
replication and led to disorder of mitosis, which further induced cell apoptosis in MDA-MB-468 and MDA-MB-231 cells.

\section{In vivo antitumor activity of $14 \mathrm{i}$}

We finally evaluated the in vivo antitumor activity of compound 14i in MDA-MB-468 (PTEN-deficient breast cancer cells) and
MDA-MB-231 (PTEN-wild type breast cancer cells) xenograft models. Compound 14i was administered orally at doses of $30 \mathrm{mg} \mathrm{kg}{ }^{-1}$ or $90 \mathrm{mg} \mathrm{kg}{ }^{-1}$ once daily for 18 consecutive days. The results showed that $\mathbf{1 4 \mathbf { i }}$ significantly suppressed tumor growth in MDA-MB-468 and MDA-MB-231 xenograft models. Compared with MDA-MB-231 xenograft model, the tumor growth inhibition rate (TGI) of MDA-MB-468 xenograft was

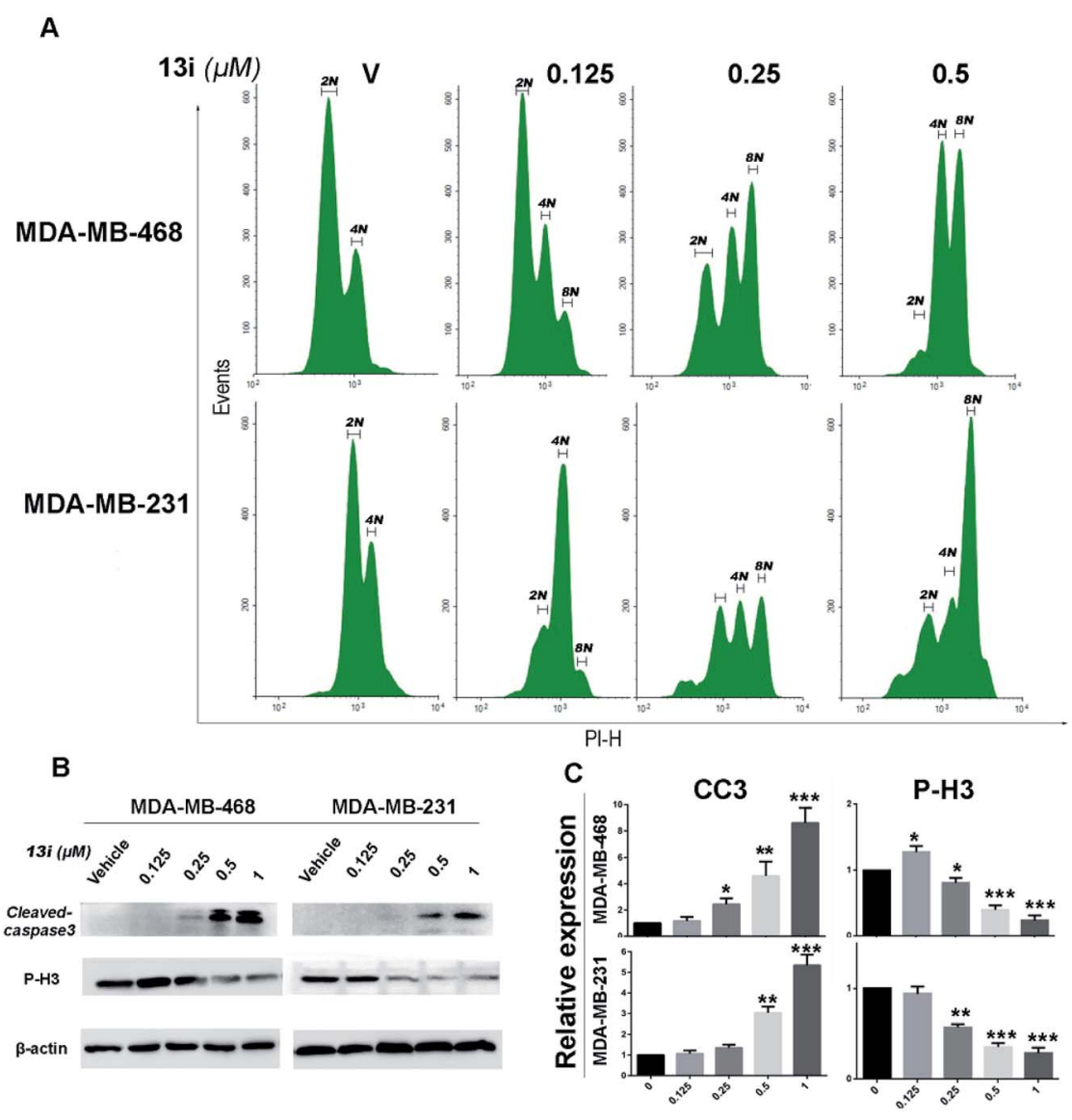

Fig. 6 (A) DNA content analysis by flow cytometry. MDA-MB-468 and MDA-MB-231 cells were treated with $14 \mathrm{i}$ or DMSO for $48 \mathrm{~h}$ prior to staining with propidium iodide. (B) and (C) MDA-MB-468 and MDA-MB-231 cells lysates were analyzed by immunoblot analysis with antibodies against $\mathrm{P}-\mathrm{H} 3$ and $\mathrm{CC} 3$ (cleaved-caspase-3).
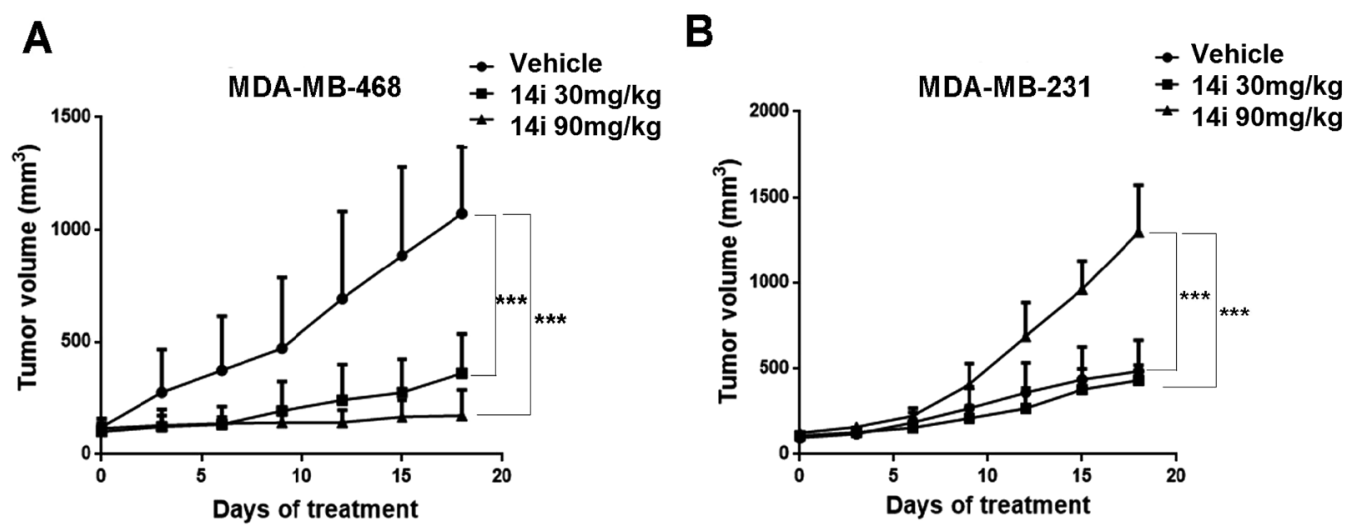

Fig. 7 In vivo antitumor efficacy of 14i against MDA-MB-468 (A) and MDA-MB-231(B) tumor xenograft models (5 mice per group). Points indicate mean tumor volume $\left(\mathrm{mm}^{3}\right)$; bars indicate SD. 
A

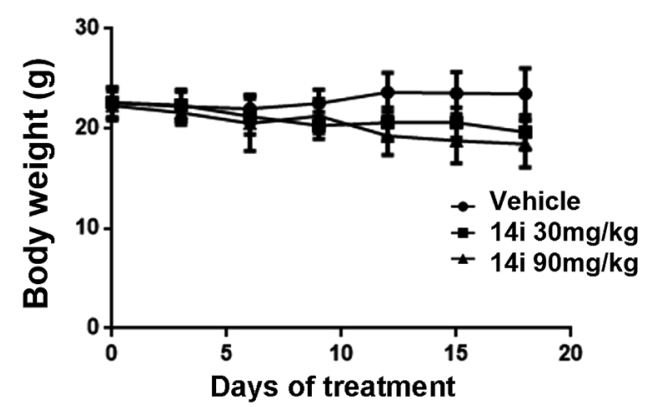

B

MDA-MB-231

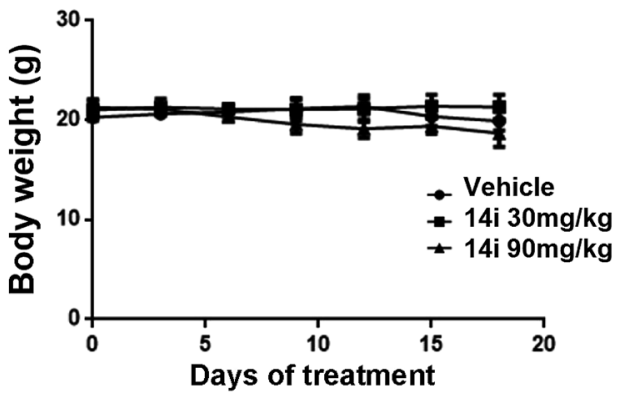

Fig. 8 Body weight measurements in vivo antitumor experiments. Note: results are expressed as the mean \pm SEM ( $n=5$ for the inhibitor-treated group, $n=5$ for the vehicle control group).

much higher, with TGI of $83.1 \%$ versus $67.6 \%$ and $68.3 \%$ versus $63.9 \%$ at the doses of $30 \mathrm{mg} \mathrm{kg}^{-1}$ and $90 \mathrm{mg} \mathrm{kg}^{-1}$ respectively (Fig. 7), which also confirmed that PTEN-deficient tumors were susceptible to PLK4 inhibitors in vivo. Moreover, no significant body weight loss was observed at both doses (Fig. 8).

\section{Conclusion}

In summary, using scaffold hopping strategy, we discovered $(E)$-4(3-arylvinyl- $1 H$-indazol-6-yl)pyrimidin-2-amine derivatives as a more concise chemotype of PLK4 inhibitors. SAR explorations and preliminary physicochemical properties assessment led to the identification of $\mathbf{1 4} \mathbf{i}$ as a new PLK4 inhibitor with potent PLK4 activity $\left(\mathrm{IC}_{50}=11.2 \mathrm{nM}\right)$ and significant antiproliferative effects $\left(\mathrm{MDA}-\mathrm{MB}-231 \mathrm{IC}_{50}=0.09\right.$ and MDA-MB-468 $\mathrm{IC}_{50}=0.06 \mu \mathrm{M}$, respectively). Besides, 14i exhibited good selectivity for PLK4 over other members of polo-like kinase family. Furthermore, 14i could perturb the centriole replication and induce disorder of mitosis as well as cancer cells apoptosis. Moreover, 14i demonstrated significant antitumor efficacy in the MDA-MB-468 and MDA-MB231 xenograft models. All these data indicated that this chemotype would be a promising starting point for the development of PLK4 inhibitors as anticancer agents and 14i would be an attractive lead compound for further optimization and evaluation.

\section{Experimental}

\section{Synthesis of 9a-9b}

To a solution of $\mathbf{8 a - 8 b}$ (40 $\mathrm{mmol})$, bis(pinacolato)-diboron $(15.2 \mathrm{~g}, 60 \mathrm{mmol})$ and KOAc $(7.84 \mathrm{~g}, 80 \mathrm{mmol})$ in 1,4-dioxane $(100 \mathrm{~mL}), \mathrm{Pd}(\mathrm{dppf}) \mathrm{Cl}_{2}(2 \mathrm{mmol})$ was added and the mixture was degassed for $5 \mathrm{~min}$. The mixture was heated to $90^{\circ} \mathrm{C}$ for $8 \mathrm{~h}$ and cooled to r.t. The mixture was diluted with ethyl acetate and filtered through celite. The filtrate was washed successively with water and brine, dried over $\mathrm{Na}_{2} \mathrm{SO}_{4}$ and concentrated. The residue was purified by chromatography eluting with Pet $:$ EtOAc $=2.5: 1$ to give products $9 \mathbf{9}-\mathbf{9 b}$.

\section{Synthesis of 11a-11d}

To a solution of $\mathbf{9 a - 9 b}(15 \mathrm{mmol}), \mathbf{1 0 a}-10 \mathrm{c}(12.5 \mathrm{mmol})$ and KOAc $(30 \mathrm{mmol})$ in 1,4-dioxane $(100 \mathrm{~mL}), \mathrm{Pd}(\mathrm{dppf}) \mathrm{Cl}_{2}(0.62$ mmol) was added and the mixture was degassed for $5 \mathrm{~min}$. The mixture was heated to $100{ }^{\circ} \mathrm{C}$ for $3 \mathrm{~h}$ and cooled to r.t. The mixture was diluted with ethyl acetate and filtered through celite. The filtrate was washed successively with water and brine, dried over $\mathrm{Na}_{2} \mathrm{SO}_{4}$ and concentrated. The residue was purified by chromatography eluting with $\mathrm{DCM}: \mathrm{CH}_{3} \mathrm{OH}=12: 1$ to afford products 11a-11d.

\section{Synthesis of 12a-12d}

11a-11d $(8.0 \mathrm{mmol})$ and $\mathrm{K}_{2} \mathrm{CO}_{3}(16 \mathrm{mmol})$ were combined in DMF $(15 \mathrm{~mL})$, and $\mathrm{I}_{2}(16 \mathrm{mmol})$ dissolved in DMF $(2 \mathrm{~mL})$ was added dropwise to the mixture, then stirred 10 hours at $65{ }^{\circ} \mathrm{C}$. The reaction was then poured into a solution of sodium dithionite $(3.0 \mathrm{~g})$ and $\mathrm{K}_{2} \mathrm{CO}_{3}(1.1 \mathrm{~g})$ in water $(50 \mathrm{~mL})$. A white precipitate formed and was stirred at room temperature for $30 \mathrm{~min}$. Product was isolated by filtration to give 12a-12d.

\section{Synthesis of $14 a-14 y, 15 a-15 d$}

To a solution of 12a-12d ( $0.36 \mathrm{mmol})$, trans-arylvinylboronates or trans-hetarylvinylboronates 13a-13y $(0.43 \mathrm{mmol})$ and cesium carbonate $(0.72 \mathrm{mmol})$ in 1,4-dioxane $: \mathrm{H}_{2} \mathrm{O}=4: 1(15 \mathrm{~mL})$, $\mathrm{Pd}(\mathrm{dppf}) \mathrm{Cl}_{2}(0.04 \mathrm{mmol})$ was added and the mixture was degassed for $5 \mathrm{~min}$. The mixture was heated to $100{ }^{\circ} \mathrm{C}$ for $8 \mathrm{~h}$ and cooled to r.t. The mixture was diluted with ethyl acetate and filtered through celite. The filtrate was washed successively with water and brine, dried over $\mathrm{Na}_{2} \mathrm{SO}_{4}$ and concentrated. The residue was purified by chromatography eluting with DCM : $\mathrm{CH}_{3} \mathrm{OH}=$ $10: 1$ to afford the title compounds $14 a-14 y, 15 a-15 d$.

\section{Kinase inhibition assays}

Kinase inhibition profiles were obtained using Kinase Profiler services provided by Reaction Biology Corporation, and ATP concentrations used are the ATP $K_{\mathrm{m}}$ of corresponding kinases. Compounds were tested in a 10 -dose $\mathrm{IC}_{50}$ mode with 3 -fold serial dilution starting at $10 \mu \mathrm{M}$.

\section{Cell lines and cell culture conditions}

All of cell lines used were purchased from American Type Culture Collection (ATCC, Manassas, VA, USA). All of them were 
cultured in RPIM 1640 or Iscove's Modified Dulbecco's Medium supplemented with $10 \%$ fetal bovine serum (FBS, Gibco, Auckland, N.Z.), penicillin-streptomycin (Life Technologies), and $4 \mathrm{mM}$-glutamine. The cell lines were cultured in a humidified atmosphere with $5 \% \mathrm{CO}_{2}$ at $37{ }^{\circ} \mathrm{C}$.

\section{Cell viability assay}

The cell viability treated with the compounds described above was measured by MTT assay. $100 \mu \mathrm{L}$ of medium containing various concentrations of compound was added to 96-well micro-plates, then cells were seeded in each well at a density of 5-10 $\times 10^{4}$ cells. After cultured for $72 \mathrm{~h}$, the cells were added 20 $\mu \mathrm{L}$ MTT solution ( $5 \mathrm{mg} \mathrm{mL}^{-1}$ ) and incubated for another $2-4 \mathrm{~h}$ at $37{ }^{\circ} \mathrm{C}$. When reached the appropriate time, the formazan crystal formed by living cells was dissolved with $50 \mu \mathrm{L}$ of the $20 \%$ SDS solution overnight. Then, the optical density was measured using Spectra MAX M5 micro-plate spectrophotometer (Molecular Devices) at $570 \mathrm{~nm}$ and the $\mathrm{IC}_{50}$ values were carried out in Graphpad Prism 5 (GraphPad Software Inc.).

\section{Western blot analysis}

The tumor cells MDA-MB-231 and MDA-MB-468 were incubated in medium containing different concentration of $\mathbf{1 4 i}$ for $48 \mathrm{~h}$. Then harvested cells washed by PBS twice were lysed in RIPA buffer (Byotime, Beijing, China) for $20 \mathrm{~min}$, then ultrasonicated and centrifugated. The protein concentrations were measured and equalized before loading. Protein was separated by SDSPAGE gels. After electrophoresis, protein was transferred onto polyvinylidene fluoride membranes (Millipore), blocked in 5\% non-fat milk for $2 \mathrm{~h}$, washed in TBS-T and incubated with specific antibodies (Cell Signaling Technology) overnight at $4{ }^{\circ} \mathrm{C}$. After incubated with the relevant secondary antibodies, the reactive bands were detected using an enhanced chemiluminescence kit (Millipore).

\section{Immunofluorescence analysis}

For immunofluorescence staining, the treated cancer cells in 8 well chamber slides (Millipore) were washed twice in PBS and fixed in $4 \%$ paraformaldehyde for $15 \mathrm{~min}$, then cells were blocked in 1\% BSA for $1 \mathrm{~h}$ at room temperature. Primary antibody in block buffer was added to cells overnight at $4{ }^{\circ} \mathrm{C}$ and washed 3 times by PBS. Goat anti-rabbit and goat anti-mouse secondary antibodies conjugated to FITC and Alexa 594 were used to detect primary antibodies. After washed twice with PBS, the cells were counterstained with DAPI, and the images were captured using a Leica confocal microscope equipped with a Leica X63oil-immersion objective.

\section{Cell cycle analysis}

For the cell cycle analysis, the 14i-treated cells were fixed and stained with PI staining solution for 5 min in the dark and then detected using flow cytometry (FCM). The data were analyzed using the NovoExpress software.

\section{Subcutaneous xenograft models}

All animal experiments have been approved by the Institutional Animal Care and Treatment Committee of Sichuan University in China (Permit number: 20160188) and were carried out in accordance with the approved guidelines. Six-week-old female BALB/c nude mice were purchased from HFK Biotechnology Company (Beijing, China). Tumors were first prepared by subcutaneously implanting $1 \times 10^{7}$ cells $/ 0.1 \mathrm{~mL}$ into the right flank region of mice. When the volume reached $200 \mathrm{~mm}^{3}$, tumors were dissected into fragments of approximated 10-20 $\mathrm{mm}^{3}$ and subsequently implanted into hind flank region of $\mathrm{BALB} / \mathrm{c}$ nude mice. When the tumor reached $80-110 \mathrm{~mm}^{3}$, mice were selected and randomized into groups for further study $(n=$ 5). Mice were given $\mathbf{1 4 i}$ and blank solvent once daily by oral gavage. Tumor size was monitored every 3 days using calipers and the volume was calculated using the following formula: tumor volume $=$ length $\times$ width $^{2} \times 0.5$.

\section{Solubility test $^{29}$}

The production of test solution: each compound was added in excess to $1000 \mu \mathrm{L}$ solvent. The drug suspensions were placed in ultrasound for $15 \mathrm{~min}$ followed by filtration to get the saturated solution. Then the test solutions were obtained by diluting the saturated solution 100 times.

The production of reference solution: adding accurate $2.000 \mathrm{mg}\left(m_{\mathrm{r}}\right)$ compound into $1000 \mu \mathrm{L}$ methanol. The solutions were placed in ultrasound for $15 \mathrm{~min}$ to dissolve completely. Then filtered and the reference solutions were obtained by diluting the filter liquor 100 times.

The concentration of each sample was measured with HPLCUV-vis apparatus. The test condition is as follows:

Chromatographic column: Venusil XBP (C18) $5 \mu \mathrm{m} 150 \AA 4.6$ $\times 250 \mathrm{~mm}$.

Mobile phase: methanol (A) and $\mathrm{pH}=6.8 \mathrm{H}_{2} \mathrm{O}(\mathrm{B})$

Injection volumes: $40 \mu \mathrm{L}$ per injection.

Column temperature: $30{ }^{\circ} \mathrm{C}$.

Pressure: $120 \mathrm{~Pa}$.

Flow rate: $1.00 \mathrm{~mL} \mathrm{~min}^{-1}$.

The calculation formula of solubility is as follows:

$C=\left(m_{\mathrm{r}} \times A_{\mathrm{t}}\right) /\left(A_{\mathrm{r}} \times 1000\right)$

$A_{\mathrm{t}}$ and $A_{\mathrm{r}}$ are respectively refer to the area of test solution's chromatographic peak and the area of reference solution's chromatographic peak.

\section{Molecular modeling ${ }^{30}$}

The binding mode of the compound 14i and PLK4 was conducted by structure based docking studies, which was carried out by using AutoDock 4.0. The structure of the receptor was taken from PDB (PDB ID: 4JXF). The binding site of the inhibitor was chosen as active site, grid dimensions were $40 \times 40 \times$ $40 \AA^{3}$, which were defined by AutoDock tools.

\section{Acknowledgements}

This work was supported by China Postdoctoral Science Foundation (No. 2015M570790, No. 2016T90860). We thank Lihua 
Zhou of State Key Laboratory of Biotherapy (Sichuan University) for NMR measurements.

\section{References}

1 G. D. Cárcer, G. Manning and M. Malumbres, Cell Cycle, 2011, 10, 2255-2262.

2 F. A. Barr, H. H. Silljé and E. A. Nigg, Nat. Rev. Mol. Cell Biol., 2004, 5, 429-440.

3 C. G. De, B. Escobar, A. M. Higuero, L. García, A. Ansón, G. Pérez, M. Mollejo, G. Manning, B. Meléndez and J. Abad-Rodríguez, Mol. Cell. Biol., 2011, 31, 1225-1339.

4 V. Archambault and D. M. Glover, Nat. Rev. Mol. Cell Biol., 2009, 10, 265-275.

5 S. M. Lens, E. E. Voest and R. H. Medema, Nat. Rev. Cancer, 2010, 10, 825-841.

6 G. C. Leung, J. W. Hudson, A. Kozarova, A. Davidson, J. W. Dennis and F. Sicheri, Nat. Struct. Biol., 2002, 9, 719724.

7 J. E. Sillibourne and M. Bornens, Cell Div., 2010, 5, 25.

8 M. Bettencourt-Dias, A. Rodrigues-Martins, L. Carpenter, M. Riparbelli, L. Lehmann, M. K. Gatt, N. Carmo, F. Balloux, G. Callaini and D. M. Glover, Curr. Biol., 2005, 15, 2199-2207.

9 J. Kleyleinsohn, J. Westendorf, C. M. Le, R. Habedanck, Y. D. Stierhof and E. A. Nigg, Dev. Cell, 2007, 13, 190-202.

10 R. Habedanck, Y. D. Stierhof, C. J. Wilkinson and E. A. Nigg, Nat. Cell Biol., 2005, 7, 1140-1146.

11 G. Salvatore, T. C. Nappi, P. Salerno, Y. Jiang, C. Garbi, C. Ugolini, P. Miccoli, F. Basolo, M. D. Castellone, A. M. Cirafici, R. M. Melillo, A. Fusco, M. L. Bittner and M. Santoro, Cancer Res., 2007, 67, 10148-10158.

12 V. D. V. Mj, Y. D. He, L. J. van't Veer, H. Dai, A. A. Hart, D. W. Voskuil, G. J. Schreiber, J. L. Peterse, C. Roberts and M. J. Marton, N. Engl. J. Med., 2002, 347, 1999-2009.

13 Z. Hu, C. Fan, D. S. Oh, J. S. Marron, X. He, B. F. Qaqish, C. Livasy, L. A. Carey, E. Reynolds, L. Dressler, A. Nobel, J. Parker, M. G. Ewend, L. R. Sawyer, J. Wu, Y. Liu, R. Nanda, M. Tretiakova, A. Ruiz Orrico, D. Dreher, J. P. Palazzo, L. Perreard, E. Nelson, M. Mone, H. Hansen, M. Mullins, J. F. Quackenbush, M. J. Ellis, O. I. Olopade, P. S. Bernard and C. M. Perou, BMC Genomics, 2006, 7, 96.

14 L. D. Miller, J. Smeds, J. George, V. B. Vega, L. Vergara, A. Ploner, Y. Pawitan, P. Hall, S. Klaar, E. T. Liu and J. Bergh, Proc. Natl. Acad. Sci. U. S. A., 2005, 102, 1355013555 .
15 R. Basto, K. Brunk, T. Vinadogrova, N. Peel, A. Franz, A. Khodjakov and J. W. Raff, Cell, 2008, 133, 1032-1042.

16 N. J. Ganem, S. A. Godinho and D. Pellman, Nature, 2009, 460, 278-282.

17 J. Mason, D. C. C. Lin, X. Wei, Y. Che, Y. Yao, R. Kiarash, D. Cescon, G. Fletcher, D. Awrey and M. Bray, Cancer Cell, 2014, 26, 163-176.

18 R. Brough, J. R. Frankum, D. Sims, A. Mackay, A. M. Mendespereira, I. Bajrami, S. Costacabral, R. Rafiq, A. S. Ahmad and M. A. Cerone, Cancer Discovery, 2011, 1, 260-273.

19 C. Tovar, B. Higgins, D. Deo, K. Kolinsky, J. Liu, D. C. Heimbrook and L. T. Vassilev, Cell Cycle, 2010, 9, 3364-3375.

20 L. W. Yao, J. V. Anzola, R. L. Davis, M. Yoon, A. Motamedi, A. Kroll, C. P. Seo, J. E. Hsia, K. K. Sun and J. W. Mitchell, Science, 2015, 348, 1155-1160.

21 E. F. Johnson, K. D. Stewart, K. W. Woods, V. L. Giranda and Y. Luo, Biochemistry, 2007, 46, 9551-9563.

22 R. Laufer, B. Forrest, S. W. Li, Y. Liu, P. Sampson, L. Edwards, Y. Lang, D. E. Awrey, G. Mao and O. Plotnikova, J. Med. Chem., 2013, 56, 6069-6087.

23 P. B. Sampson, Y. Liu, N. K. Patel, M. Feher, B. Forrest, S. W. Li, L. Edwards, R. Laufer, Y. Lang and F. Ban, J. Med. Chem., 2015, 58, 130-146.

24 P. B. Sampson, Y. Liu, B. Forrest, G. Cumming, S. W. Li, N. K. Patel, L. Edwards, R. Laufer, M. Feher and F. Ban, J. Med. Chem., 2015, 58, 147-169.

25 S. W. Li, Y. Liu, P. B. Sampson, N. K. Patel, B. T. Forrest, L. Edwards, R. Laufer, M. Feher, F. Ban, D. E. Awrey, R. Hodgson, I. Beletskaya, G. Mao, J. M. Mason, X. Wei, X. Luo, R. Kiarash, E. Green, T. W. Mak, G. Pan and H. W. Pauls, Bioorg. Med. Chem. Lett., 2016, 26, 4625-4630.

26 I. Lohse, J. M. Mason, P. J. Cao, M. Pintilie, M. R. Bray and D. W. Hedley, Oncotarget, 2016, 8, 3064-3071.

27 B. Yu, Z. Yu, P. P. Qi, D. Q. Yu and H. M. Liu, Eur. J. Med. Chem., 2015, 95, 35-40.

28 P. Leeson and B. Springthorpe, Nat. Rev. Drug Discovery, 2007, 6, 881-890.

29 G. Yao, Q. Yao, Z. Xia and Z. Li, J. Chem. Thermodyn., 2017, 179-186.

30 G. M. Morris, R. Huey, W. Lindstrom, M. F. Sanner, R. K. Belew, D. S. Goodsell and A. J. Olson, J. Comput. Chem., 2009, 30, 2785-2791. 